\title{
KREIRANJE INOVATIVNIH ISTRAŽIVAČKIH PITANJA: PERSPEKTIVA PROBLEMATIZACIJE ${ }^{1}$
}

\begin{abstract}
Apstrakt: Polazeći od ideje da su istraživanja u obrazovanju postala dominantno inkrementalno-konformistička, u radu se problematizacija afirmiše kao strategija generisanja inovativnih istraživačkih pitanja. Rad započinje debatovanjem o interakciji činilaca različitih nivoa koji, pored motiva za kreiranjem relevantnog znanja, mogu imati centralni značaj u formiranju habitata i habitusa istraživača u obrazovanju. Drugi, centralni deo rada posvećen je analiziranju konstitutivnih komponenata (faza) problematizacije koja se određuje kao metodološko sredstvo kritičkog i refleksivnog preispitivanja eksplicitnih i prećutnih pretpostavki prevalentnih teorija. Konačno, rad se zaključuje konstatacijom da uprkos sveprisutnoj tendenciji istraživača da realizuju standardizovane i izomorfne studije, moguće je istraživanja obrazovanja "vratiti na pravi put" koji podrazumeva kreiranje originalnog naučnog znanja koje je društveno i pedagoški relevantno.
\end{abstract}

Ključne reči: istraživanja u obrazovanju, istraživačka pitanja, problematizacija, kritičko mišljenje

\section{UVOD}

Činjenica je da dobra istraživanja u obrazovanju nisu obeležena samo rigoroznim uvažavanjem adekvatnih metodoloških standarda, već i inovativnim istraživačkim pitanjima i korisnim (relevantnim) rezultatima. Istraživači u obrazovanju imaju pravo i obavezu da razumeju šta rade, da budu kritični prema svojoj pretpostavljenoj ulozi, i da istražuju probleme koji su smisleni ne samo drugima nego i njima samima (Hostetler, 2005). Međutim, bez obzira što su uticajna istraživanja ona koja problematizuju do tada uglavnom neproblematizovane aspekte dobro utemeljenih teorija (Van de Ven, 2007), ostaje činjenica da istraživači u obrazovanju nastavljaju rutinski, mimetički i nekritički da reprodukuju te teorije.

Rad je nastao kao rezultat istraživanja u okviru projekta Značaj participacije u društvenim mrežama za prilagođavanje evrointegracijskim procesima (br. 179037) koji je finansiran od strane Ministarstva prosvete, nauke i tehnološkog razvoja Republike Srbije

Stefan Ninković, stefanninkovic985@gmail.com 
Konkretnije rečeno, identifikovanje ili kreiranje praznina u postojećoj literaturi postalo je preferirani - ili barem dominantno korišćeni - način formulisanja istraživačkih pitanja (Alvesson \& Sandberg, 2011; 2013). U tom smislu, opravdano je postaviti nekoliko pitanja. Jesu li istraživanja u obrazovanju izgubila svoj put? Da li istraživači u obrazovanju imaju da kažu nešto što značajno doprinosi razumevanju obrazovnih fenomena, sa određenom relevancijom sa obrazovnu praksu? Da li su istraživanja u obrazovanju postala rutinska (neinspirativna), izomorfna i irelevantna?

Osnovna intencija ovog rada jeste predstavljanje problematizacije kao modusa generisanja zanimljivih istraživačkih pitanja. Rad započinje analiziranjem činilaca koji, pored motiva za kreiranjem društveno i pedagoški relevantnog znanja, mogu imati centralni značaj u formiranju habitata $i$ habitusa istraživača $u$ obrazovanju. Drugi, centralni deo rada je posvećen je analiziranju konstitutivnih komponenata (faza) problematizacije koja se određuje kao metodološko sredstvo kritičkog i refleksivnog preispitivanja pretpostavki prevalentnih teorija. Konačno, rad se zaključuje konstatacijom da uprkos sveprisutnoj tendenciji istraživača da realizuju standardizovane i izomorfne studije, moguće je istraživanja obrazovanja "vratiti na pravi put" koji podrazumeva kreiranje originalnog naučnog znanja koje je relevantno za potrebe i teorije i prakse.

\section{DOMINACIJA KONFORMISTIČKO-KONZERVATIVNIH ISTRAŽIVANJA}

Intenzivna popularnost inkrementalnih istraživanja u društvenim naukama je iznenađujuća, posebno zbog činjenice da studije koje problematizuju eksplicitne tvrdnje i komplekse implicitnih pretpostavki prevalentnih teorija privlače najviše pažnje i postaju uticajne. Kriveći "sve" za takvo stanje, Alvesson i Sandberg (Alvesson \& Sandberg, 2013) ističu kako je postalo očigledno da se mnogi istraživači trude da slede trendove, internalizuju norme naučne oblasti, i nastoje da budu lojalni članovi naučne zajednice. Takvo stanje ukazuje na prisustvo akademskog tribalizma (Becher \& Trowler, 2001) koji podrazumeva autoreferentno funkcionisanje visoko specijalizovanih grupa istraživača. U tom kontekstu, nedostaje istraživački rad koji bi odstupao od metodoloških regularnosti, koji bi kreirao naučne probleme, $\mathrm{i}$ informisano kritikovao pretpostavke postojećih teorija.

Po Sandbergu i Alvessonu (2011) istraživači nastavljaju dominantno da kreiraju istraživačka pitanja na osnovu uočavanja nedovoljno istraženih oblasti i implikacija vladajućih teorija zato jer:

- uvažavanje standardizovanih formi pisanja i publikovanja je lako;

- "dobrovoljno" i nekontroverzno emuliranje drugih znači izbegavanje odstupanja, konfuzije i sankcija;

- prestižni časopisi ohrabruju takvu istraživačku praksu;

- alternativni načini generisanja istraživačkih pitanja zahtevaju više vremena i energije. 
Imajući na umu ove trendove, moguće je govoriti o pojavljivanju intelektualnih habitata i habitusa istraživača u mnogim oblastima društvenih nauka (Alvesson \& Sandberg, 2014). Habitat legitimizuje probleme istraživanja, određuje ko će „naseliti” ograničenu istraživačku teritoriju, formuliše vladujuće metodološke konvencije i stilove koje je poželjno slediti. Pored toga, habitat kognitivno, emocionalno i egzistencijalno pomaže organizovanje realnosti u distinktivno istraživačko područje. Sa druge strane, habitus definiše očekivane metodološke kompetencije i strateški reguliše formiranje identiteta istraživača, uobičajeno kao opreznog, temeljnog, disciplinovanog, minucioznog i visoko specijalizovanog.

Alternativno, problematizujući istraživački pristup podrazumeva određeni stepen intelektualnog nomadstva koji se manifestuje kretanjem raznovrsnijom interdisciplinarnom teritorijom čime istraživač proširuju sopstvene perspektive i otkriva nove ideje, teorije i metode. Alvesson i Sandberg (2014) predlažu sledeće principe intelektualnog nomadstva:

- relativna posvećenost samo jednoj paradigmi;

- razvijanje refleksivnog istraživačkog identiteta i problematizovanje sopstvenog rada;

- kultivisanje pluralne istraživačke mreže interakcija sa ljudima kojima imaju drugačije osnovne reference;

- nelojalnost prema vlastitom istraživačkom području i spremnost na kontinuirano problematizovanje pretpostavki dominantnih teorijskih pozicija uključujući i svoju;

- aktivna upotreba vokabulara koji je drugačiji u odnosu na maternji naučni jezik;

- motivisanost da se ostvari radikalni doprinos u odnosu na umerene/ inkrementalne ciljeve.

U daljem tekstu biće komentirisane osnovne komponente problematizacije koja, u osnovi, predstavlja polimorfno kritičko analiziranje i evaluiranje pretpostavki dominantnih paradigmi, intelektualnih tradicija, istraživačkih programa, teorija, itd. Polimorfno u ovom slučaju referira na raznovrsnost istraživačkih pristupa, stilova i istraživačkih pitanja. To, dakle, znači da istraživači koji imaju afinitet prema problematizaciji prepoznaju i prihvataju nejasnoće i ambivalentnost, paradokse i misteriju, izbegavaju preurarenje zaključke i pretpostavke neupitnog autoriteta.

\section{PROCES PROBLEMATIZACIJE: OSNOVNE KOMPONENTE}

Mnogi istraživači obrazovanja smatraju da su kvalitativne i kvantitativne metode međusobno kompatibilne a ne nesamerljive (Howe, 2009), da je istraživačka praksa daleko haotičnija u odnosu na njene udžbeničko-enciklopedijske opise (Law, 2004), i priznaju da istraživanja ne mogu generisati direktno aplikativna saznanja (Biesta, 2010). Međutim, uprkos naznačenim uvida, ostaje činjenica da 
identifikovanje neobrađenih područja i reprodukovanje pretpostavki dobro utemeljenih teorija predstavljaju najčešće primenjivane načine kreiranja istraživačkih pitanja. Očigledna alternativa je problematizacija u čijem kritičkom fokusu su premise, perspektive, konvencije, jezik i drugi elementi dominantnih teorija.

Kako je već u uvodu sugerisano, problematizacija je zasnovana na praksi kritičkog mišljenja koje ko će „,atakuje na ono što uobičajeno” (Meklaren, 2013: 258). Takva usresređenost na prepoznavanje i propitivanje domašaja ideja, posebno prećutnih teorijskih i metodoloških pretpostavki, obuhvata kritički dijalogizam i defamilijarizaciju. Sa druge strane, problematizacija je usko povezana sa konceptom refleksivne metodologije koji pažnju usmerava ka unutrašnjosti ličnosti istraživača, relevantnoj istraživačkoj zajednici, inelektualnoj i kulturnoj tradiciji, centralnoj važnosti i problematičnoj prirodi uloge jezika i narativa u istraživačkom kontekstu (Alvesson \& Sköldberg, 2009).Takva konjukcija implicira da sukobi paradigmi i ostale trajne teorijske debate predstavljaju važne metodološke resurse otvaranja i kritičkog razmatranja pretpostavki koje su u osnovi prevalentnih teorija, uključujući, u određenom stepenu, i problematizovanje rada samog istraživača.

Činjenica je da je veoma teško, ako ne i nemoguće, realizovati istraživanje neimpregnirano prekoncepcijama istraživača; uvek se istražuje u nekom referencijalnom okviru, paradigmi, istraživačkom programu, političko-ideološkom kontekstu, intelektualnoj tradiciji itd. Referencijalni okvir istraživača segmentira i klasifikuje opažljivu stvarnost na neki specifičan način, a takva organizacija iskustva po pravilu je nesvesna, arbitrarna i apriorna (Milenković, 2006). Preliminarno se može reći da za razliku od naivne i uprošćene neopozitivističke predstave o objektivnom i vrednosno neutralnom istraživaču, ovde se njegovo refleksivno angažovanje, njegova samoreferencijalnost, podrazumeva kao osnovno sredstvo postizanja naučnosti. U osnovi, "kritičko znanje se shvata uvek kao otvoreno, otkriveno, neodređeno i nedovršeno" (Meklaren, 2013: 292). Međutim, Fajerabend direktno postavlja pitanje:

Kako uopšte možemo ispitivati nešto što neprestano upotrebljavamo? Kako možemo analizirati termine kojima obično izražavamo naše najjednostavnije i najdirektnije opservacije i otkriti njihove presupozicije? Kako možemo otkriti svet koji pretpostavljamo kada postupamo na način na koji to činimo? Odgovor je jasan: ne možemo ga otkriti iznutra. Potrebno nam je vanjsko merilo kritike, skup alternativnih pretpostavki (Feyerabend, 1987: 22).

Ishodišna tačka metodologije problematizacije jeste artikulisanje i kritičko valorizovanje pretpostavki postojećih teorija o predmetu istraživanja . Osnovne komponente (faze) problematizacije su: 1) identifikovanje relevantnog domena literature, 2) identifikovanje i artikulisanje pretpostavki, 3) njihovo evaluiranje, 4) razvijanje alternativnog skupa mogućnosti, 5) njihovo razmatranje u odnosu na auditorijum, 6) evaluiranje alternativnih pretpostavki (Alvesson \& Sandberg, 2011; 2013; Sandberg \& Alvesson, 2011). Međutim, bez obzira na tendenciju da se funkcionalno odrede njene konstitutivne komponente, ostaje činjenica da pro- 
blematizacija ne može biti redukovana na standardizovanu ili čak rutiniziranu proceduru, budući da nužno podrazumeva dijalektički i dijaloški proces. To znači da, sa jedne strane, ne može biti govora o principu "sve je moguće" u primeni problematizacije, a, sa druge strane, sigurno je nemoguće govoriti o savršenom razumevanju i primeni problematizacije. Ona je, kao dinamički nelinearni proces, uvek situirana u realitet istraživačke prakse. U širem smislu, problematizacija je pri svakoj primeni ponovno definisana, ona postaje to što jeste tek u rukama korisnika (Sandelowski, 2010).

\section{Identifikovanje domena literature koji će biti problematizovan}

Problematizujuća istraživanja obično obuhvataju pregled užeg spektra referenci (Alvesson \& Sandber, 2011) i kritičko čitanje ključnih tekstova koji zasnivaju određeni pristup, sa ciljem identifikacije i preispitivanja pretpostavki na kojima se temelji određeni domen literature. To, dakle, znači da mejnstrim norma prema kojoj je apsolutno neophodno dovesti u vezi sopstvenu studiju sa većinom relevantne literature zapravo inhibira problematizaciju.

\section{Identifikovanje i artikulisanje pretpostavki}

U pojedinim slučajevima moguće je uočiti eksplicitne pretpostavke na kojima su bazirane koncepualizacije teme proučavanja, poput one da su lični atributi nastavnika osnovni korelat postignuća učenika (Kennedy, 2010; Leana \& Pil, 2006). Međutim, u pozadini postulata se nalaze prećutne premise koje se obično percipiraju kao nekontroverzne. Prema Alvessonu i Sandbergu (2013) postoji širok spektar pretpostavki koje se mogu problematizovati: od onih koje zagovaraju predstavnici partikularne naučne teorije do onih od kojih polaze svi pripadnici jedne naučne oblasti, pa čak i zagovornici različitih paradigmi.

Neke od pretpostavki moguće je artikulisati paralelnim proučavanjem različitih teorijskih stanovišta i intelektualnih tradicija kako bi se registrovali njihovi zajednički aspekti. Druga mogućnost je ispitivanje sporova između prividno veoma različitih teorijskih pozicija, sa ciljem fokusiranja nespominjanih tema - pitanja o kojima nisu vođene debate. Konačno, može biti korisno sagledavanje različitih interesa i vrednosti, kontradikacija i dilema u istraživanom polju. Na primer, kontradikcije između liderstva i autonomije, slobodnog izražavanja i političke korektnosti, predstavljaju jasne ilustracije.

Postoje različite heurističke tehnike identifikovanja i artikulisanja implicitnih teorijskih stavova određenog domena literature. Iako fokusiranje specifičnih tipova pretpostavki može biti veoma korisno, produktivnije je varirati fokus. Međutim, teško je negirati činjenicu da identitet i preferencije istraživača mogu dovesti do fiksacije singularne perspektive. U tom smislu, važni preduslovi refleksivnosti istraživača su njegova muliperspektivnost, defamilijarizacija i njegovo kontinuirano teorijsko-metodološko repozicioniranje. 


\section{Evaluiranje artikulisanih pretpostavki}

Prilikom ocenjivanja artikulisanih pretpostavki u obzir se uzimaju pre svega one ideje koje ne doprinose boljem razumevanju predmeta proučavanja, ali su i dalje, manje ili više, nekritički prihvaćene (Alvesson \& Sandberg, 2013). Bolje su one pretpostavke koje doprinose boljem razumevanju u proučavanom domenu stvarnosti. Pojam "dobro razumevanje" ovde obuhvata tri međusobno preklapajuća aspekta. Jedan se odnosi na pitanje da li je identifikovana pretpostavka istinita/ pogrešna, obmanjujuća, preuska ili na neki drugi način rezultira pogrešnim razumevanjem predmeta istraživanja. Drugi aspekt je povezan sa pitanjem da li uočena pretpostavka pruža nove uvide i da li inspiriše nove istraživačke programe. Ovde je potrebno naglasiti da izbor i trajnost naučnih pretpostavki nije potpuno određen činjenicama već i nizom nenaučnih faktora (Milenković, 2007). I konačno, aspekt praktične relevancije određene pretpostavke odnosi se na njen uticaj na menjanje i unapređivanje prakse.

\section{Razvijanje alternativnih pretpostavki}

Razvijanje alternativnih pretpostavki direktno je zasnovano na prethodnim principima procesa problematizacije. Jedan od načina generisanja zanimljivih alternativa može biti Fajerabendov postupak protivindukcije koji se svodi na "uvođenje i razrađivanje hipoteza koje su nedosledne dobro utemeljenim teorijama i/ili dobro utemeljenim činjenicama" (Feyerabend, 1987: 21). Druga mogućnost je upotreba analogija i povlačenje njihovih implikacija. Kao što Abott (Abbott, 2004) sugeriše, istraživač može kreirati analogiju kako bi uz pomoć modela $\mathrm{i}$ koncepata iz potpuno druge oblasti bolje pojmovno strukturirao vlastiti predmet proučavanja. Na primer, ideja socijalnog kapitala je omogućila istraživačima da fokusiraju ulogu kvaliteta i kvantiteta profesionalne interakcije nastavnika (Leana \& Pil, 2006). Jedan od primera takvog načina korišćenja analogije jeste Bronfenbrenerova (1997) originalna koncepcija razvojne interakcije individue i njenog okruženja.

Heuristik pravljenja zaokreta (Abbott, 2004) se takođe može upotrebljavati. Na primer, mnogima je samorazumljivo da je rizično ponašanje mladih opasno i štetno. Međutim, da li je moguće pretpostaviti da su adolescenti obično svesni rizika u koji se upuštaju i da njihovo ponašanje ne može biti objašnjeno neinformisanošću ili nezanjem. Time se rekonceptualizuje tema istraživanja i artikulišu se alternativne pretpostavke na kojima je bazirano naše razumevanje rizičnog ponašanja adolescenata.

\section{Razmatranje pretpostavki u odnosu na auditorijum}

Recepcija generisanih alternativnih pretpostavki direktno zavisi od upoznatosti sa trenutnim intelektualnim interesima publike. Ovo je kompleksno pitaje jer, po 
definiciji, publika kojoj su alternativne pretpostavke namenjene nije homogena grupa ljudi. Važno je ostvariti balans između insistiranja na slabostima opšteprihvaćenih pretpostavki o predmetu istraživanja i apostrofiranja tačaka slaganja i zajedničkih ciljeva.

\section{Evaluiranje alternativnih pretpostavki}

Interesne grupe o kojima treba voditi računa prilikom evaluiranja alternativnih pretpostavki su finansijeri istraživanja, studenti, praktičari, i potencijalni proučavani. Uspešnost problematizacije je manje bazirana na metodološkoj strogosti i empirijskoj evidenciji, a više na iskustvu interesantnosti. Davis (Davis, 1971, prema Alvesson \& Sandberg, 2013) govori o tri moguće reakcije auditorijuma na predložene alternativne ideje.

1.To je očigledno! Ukoliko alternativne pretpostavke u velikoj meri potvrđuju stavove auditorijuma.

2.To je apsurdno! Ako, međutim alternativne pretpostavke negiraju sve pretpostavke auditorijuma, verovatno je da će biti diskvalifikovane kao neverovatne. U oba prethodna slučaja reakcije ukazuju na neuspešnost problematizacije.

3.To je zanimljivo! Ovo je idealna reakcija do koje dolazi kada alternativne pretpostavke paralelno uvažavaju i negiraju neke od ideja koje zagovaraju članovi auditorijuma. U tom smislu, interesantnost istraživačkih pretpostavki i pitanja je direktno uslovljena činjenicom da li se nalaze "negde između" onoga što se smatra apsurdnim i onoga što se percipira kao očigledno. Heath i Heath (2007) navode da se kao osnovna obeležja uticajnih ideje mogu izdvojiti sledeća: razumljivost, neočekivanost, konkretnost, kredibilnost, emocionalnost i narativnost. U tome je, između ostalog, moguće tražiti razloge zašto se sve češće apostrofira činjenica da rezultati pedagoških istraživanja nisu u dovoljnoj meri iskorišćeni za potrebe menjanja i unapređivanja vaspitno-obrazovne prakse (Ninković i Knežević Florić, 2014).

\section{PRIMENA METODOLOGIJE PROBLEMATIZACIJE}

Upotreba problematizacije biće ilustrovana posredstvom primera teorijskoiskustvenog okvira rizičnih i protektivnih činalaca u socijalnom razvoju dece $\mathrm{i}$ mladih. Preciznije rečeno, prikaz problematizacije će fokusirati rad Hawkinsa, Catalana i Millerove (Hawkins, Catalano, \& Miller, 1992) u kojem je po prvi put sistematski izložen koncept etioloških činilaca koji su povezani sa problemima ponašanja dece i mladih. Sam rad je veoma uticajan (prema Google Scholar-u citiran je preko 5000 puta) i niz ideja koje su u njemu predstavljene se i danas nalazi u centru istraživačke pažnje. 
Uprkos činjenici da teorijski tekstovi nikada ne mogu predstaviti svu raznovrsnost istraživačke prakse, ovde izneta interpretacija problematizacije će obuhvatati sve komponente opisane u prethodnom delu rada. U svakom slučaju treba istaći da idiosinkratičnu prirodu problematizacije nije moguće potpuno formalizovati na nivou teksta sa metodskim preporukama za izvođenje istraživanja. Zapravo, svako nastojanje u pravcu standardnog definisanja i metodološkog formalizovanja problematizacije zanemaruje činjenicu da istraživačka praksa ne postoji nezavisno od istraživača (Sandelowski, 2010).

\section{Identifikovanje domena literature}

U posebnom fokusu Hawkinsa i saradnika jeste identifikovanje prekursora koji dovode do konzumiranja alokohola i drugih psihoaktivnih supstanci kod adolescenata. Faktori rizika predstavljaju činioce koji se "događaju pre konzumiranja psihoaktivnih supstanci i statistički su povezani sa povećanjem verovatnoće konzumiranja droga" (Hawkins et al., 1992: 65). Sa druge strane, postoje činioci koji svojim delovanjem "moderiraju ili posreduju efekte izloženosti riziku" (Hawkins et al., 1992: 86), a koji se označavaju kao protektivni. Upravo zbog činjenice da pojedini faktori rizika nisu promenljivi, istraživanja protektivnih činilaca su od velikog značaja u kreiranju i izboru preventivnih intervencija. Hawkins i saradnici smatraju da njihova koncepcija "pruža ekplanatorni okvir...u pogledu rizičnih i protektivnih faktora za konzumiranje droga tako što pretpostavlja uzročne veze između varijabli koje vode ka ili od konzumiranja psihoaktivnih supstanci (Hawkins et al., 1992: 87).

\section{Identifikovanje pretpostavki}

Hawkins i saradnici ekpliciraju da je njihova bazična ideja da različiti socijalni i individualni činioci oblikuju socijalni razvoj adolescenata, i preporučuju da preventivna praksa bude zasnovana na konceptu rizičnih i zaštitnih činilaca. Druge, manje očigledne, rukovodeće pretpostavke prisutne u njihovom radu su:

1.implicitno redukovanje poželjnih razvojnih ishoda na odsustvo rizičnog ponašanja adolescenata;

2.neopozitivističko stanovište o linearnim vezama rizičnih/protektivnih činilaca i socijalnog ponašanja adolescenata;

3. stimulativna okruženja, po definiciji, rezultiraju pozitivnim razvojnim ishodima, dok negativna ili stresna okruženja rezultiraju neželjenim razvojnim ishodima;

4.rizična ponašanja adolescenata su isključivo štetna, opasna i ugrožavajuća. 


\section{Evaluiranje artikulisanih pretpostavki}

Od momenta kada je načelno prihvaćen pristup javnog zdravlja u prevenciji poremećaja u ponašanju i rizičnih ponašanja dece i mladih, brojne studije orijentisane ka njegovom potvrđivanju rezultirale su značajnim uvidima. Dakle, naša namera nije da pružimo obrazloženje kako istraživači treba da napuste taj istraživački program. Međutim, zbog činjenice da formulisanje zanimljivih istraživačkih pitanja pretpostavlja problematizaciju, bilo bi korisno zauzeti kritičku poziciju i dovesti u pitanje domete pretpostavki koje pokreću istraživačke napore u poslednjih 20 -ak godina. Ne tvrdimo da su rukovodeće pretpostavke koncepta rizičnih i protektivnih činilaca pogrešne niti ih negiramo, ali umesto njihovog daljeg reprodukovanja, prikladnije je generisati i sagledati alternative, odnosno raditi na njihovom empirijskom proveravanju.

Kada reč o pretpostavci 1, moguće je postaviti pitanje da li adekvatno je redukovanje pozitivnih razvojnih ishoda mladih na nivo odsustva problema i poremećaja u socijalnom ponašanju. Sve češće se problematizuje ideja da ukoliko deca i mladi nemaju socijalnih i emocionalnih problema razvoj dolazi sam po sebi, prirodno. Sve je više onih koji postavljaju pitanje da li su mladi oslobođeni problema zaista pripremljeni za život (Bašić, 2009). Baš kao što su akademske kompetencije važne, ali nisu dovoljne, tako i prevencija problema nije samo po sebi dovoljna. Sa razvojem koncepta pozitivnog razvoja mladih eksplicirana je organičenost i neodrživost prevencije kao cilja, odnosno jače se fokusira podsticanje razvojnih prednosti dece i mladih.

Koncept rizičnih i protektivnih činalaca neposredno je ukorenjen u ekosistemskoj perspektivi i pozitivističkoj epistemologiji koja podrazumeva to da postoje predvidljive i linearne relacije rizika/zaštitnih činilaca i razvojnih ishoda (Ungar, 2004). Međutim, šta ako veze između pretpostavljenih etioloških faktora i razvoja adolescenata nisu linearne i jednoznačne? Čak i najsofisticiraniji longitudinalni nacrti nisu u stanju da identifikuju kauzalne relacije između rizičnih/protektivnih činalaca i socijalnog ponašanja adolescenata (Lösel \& Farrington, 2012). U osnovi, direktni/indirektni faktori rizika jesu verovatni, a ne savršeni prediktori poremećaja u ponašanju i rizičnih ponašanja dece i mladih. To, na primer, znači da rano ispoljavanje antisocijalnog ponašanja predstavlja dobar prediktor delinkvencije u adolescenciji, ali ne i nužan uzrok. Siromaštvo može (ali ne mora) da dovede do slabog uspeha u školi koji posledično može biti prediktor delinkventnog ponašanja u kasnijem uzrastu. Sa druge strane, faktori rizika mogu biti međusobno relativno nezavisni, ali isto tako mogu biti u dinamičnoj interakciji. Efekat različitih faktora rizika je obično aditivan, ali može biti multiplikativan ili eksponencijalan (Lösel \& Farrington, 2012).

U koncept rizičnih i zaštitnih činilaca je inkorporiran pojam optimalnog razvoja koji sadrži normativna očekivanja da adolescenti treba da postanu postanu zrele, autonomne, samoregulisane, fizički zdrave i srećne osobe. Nasuprot tome, biti nesiguran, impulsivan, antisocijalan, sklon riziku jesu neželjeni razvojni is- 
hodi. Međutim, ovu pretpostavku ekplicitno problematizuje evoluciona perspektiva prema kojoj pojmovi adaptivnog i optimalnog razvoja ne mogu biti poistovećeni (Pluess \& Belsky, 2013). Prema postavkama evolucione koncepcije razvoja, averzivni životni uslovi ne remete već usmeravaju razvoj ka strategijama koje su adaptivne u takvim okolnostima. Konačno, razvojne adaptacije na visokostresne okolnosti omogućavaju „uzimanje najboljeg iz loše situacije”, čak iako „najbolje” može i dalje podrazumevati ponašanja koja ugrožavaju pojedinca i njegovo okruženje (Ellis, et al., 2012; Pluess \& Belsky, 2013).

Opravdano potencirajući štetnost poremećaja u ponašanju i rizičnog ponašanja adolescenata, koncept rizičnih i protektivnih činilaca potpuno prenebregava pitanje motivacije za takvim ponašanjem. U velikoj meri ignoriše se činjenica da su brojni, objektivno štetni, oblici socijalnog ponašanja adolescenata funkcionalni. Poznato je, na primer, da rizična ponašanja mladih ne mogu biti objašnjena njihovom nesposobnošću da shvate potencijalne posledice takvog ponašanja (Reyna \& Farley, 2006). Kao što Steinberg (Steinberg, 2008) navodi, a suprotno popularnoj percepciji, mladi su potpuno svesni svoje ranjivosti i štetnosti određenih vidova ponašanja. Moguće je postaviti pitanje, ako tinejdžeri tačno opažaju rizik, zašto su mu ipak tako skloni? Čini se da mladi preuzimaju rizik ne zato što ne razumeju opasnosti, već zato što drugačije vrednuju potencijalne nagrade povezane sa rizičnim ponašanjem.

\section{Razvijanje alternativnih pretpostavki}

Naredni korak jeste formulisanje seta alternativnih pretpostavki o predmetu istraživanja. Generisanje novih ideja je po pravilu bazirano na eklektičkom korišćenju različitih teorijskih stavova kao referentnih tačaka i izvora problematizacije. Jedna od mogućih alternativnih pozicija jeste koncept pozitivnog razvoja mladih (Bašić, 2009) koji proširuje pojam optimalnog razvoja i implicira da podsticanje socio-kognitivnog angažovanja predstavlja najefikasnu strategiju za prevenciju problema u adolescenciji. Polazeći od ovog stanovišta, umesto fokusiranja problema i patologije, moguće je pretpostaviti da je adolescencija period izuzetne socio-kognitivne fleksibilnosti koju je neophodno adekvatno kanalisati.

Kada je reč o pretpostavci da stresna okruženja uslovljavaju negativne razvojne ishode pa tako i rizična ponašnja adolescenata, moguće je postaviti radikalno drugačiju hipotezu da stresne životne okolnosti dovode do razvoja ponašanja koja su adaptivna (funkcionalna) u stresnim okolnostima. Prema postulatima evolucionog razvojnog modela, stresna okruženja podstiču razvoj bržih životnih strategija (,živeti sada i odmah”). To, dakle, znači da adolescenti koji ispoljavaju eksternalizovane probleme u ponašanju - nasilni su, rano stupaju u seksualne odnose, konzumiraju psihoaktivne supstance - nisu manje funkcionalni od vršnjaka koji odrastaju u stimulativnim socijalnim okruženjima (Ellis et al., 2012). 
Pretpostavka 3 prema kojoj je rizično ponašanje isključivo štetno takođe može biti problematizovana. Ilustrativan je primer nasilnog ponašanja adolescenata. Naime, brojni programi protiv nasilja u školama polaze o stereotipnog uverenja o socijalnoj nekompetentnosti i kognitivnim deficitima nasilnih učenika. Međutim, novija istraživanja prepoznaju ulogu nasilnog ponašanja u ostvarivanju statusa $i$ dominacije u mreži vršnjaka (Ellis et al., 2012). Finski nacionalni program prevencije nasilja u školi KiVa (Kärnä et al., 2011) je uspešan jer je utemeljen na dve pretpostavke: a) siledžijstvo je barem delimično motivisano dobijanjem visokog statusa i moći, i b) nasilno ponašanje je grupni proces i vršnjaci vrše snažan uticaj na njegovu održivost u školskom okruženju. Cilj ovog programa je da kroz pozitivne promene u ponašanju vršnjaka redukuje potencijalne nagrade za nasilne učenike i samim tim njihovu motivaciju da se tako ponašaju. U skladu sa navedenim, očigledno je da efikasnost socijalnopedagoških intervencija zavisi od njihove kongruentnosti sa motivacionim i emocionalnim tendencijama adolescenata.

Dalje, moguće je postaviti ekonomsku analogiju: rizična ponašanja adolescenata mogu biti korisna i štetna. Saobrazno tome, negativne posledice se obično procenjuju u odnosu na potencijalne benefite. Na primer, neke oblici visokorizičnog ponašanja mogu rezultirati vremenski bliskim dobitima (visok status u vršnjačkoj grupi), ali duguročnim gubicima (napuštanje školovanja). U tom smislu, bihejvioralni ekolozi, baš kao i ekonomisti, odricanje od dugoročnih benefita tumače imajući u vidu neposredne koristi određenog ponašanja. S druge strane, dugoročne strategije primat daju dugoročnim ulaganjima u indirektne koristi. Iako konvencionalna uverenja impliciraju da je dugoročno planiranje poželjno, ono nije uvek isplativo. Naime, u velikoj meri od konteksta zavisi da li će ljudi ostvariti dugočne ciljeve, bez obzira na svoje napore.

Za razliku od ideje da su prosocijalno i antisocijalno ponašanje u negativnoj korelaciji moguće je pretpostaviti da su oba obrasca društvenog ponašanja u funkciji ostvarivanja istih ciljeva (Ellis et al., 2012). U prilog tome govore i nalazi nekih novijih istraživanja koja pokuzuju da nasilni adolescenti nisu socijalno nekompetentni, već ispoljavaj socijalne veštine i obično su popularni među vršnjacima (Caravita, Di Blasio, \& Salmivalli, 2009). Posmatrano iz te perspektive, može se pretpostaviti da neće biti korelacije, ili će čak postojati pozitivna povezanost između korišćenje prosocijalnih i antisocijalnih strategija ponašanja (Ellis et al., 2012).

Bez namere da se predstave specifična istraživačka pitanja, ilustrovano je kako se kroz problematizaciju ključnog teksta i njegovih osnovnih ideja i pojmova može doći do alternativnih pretpostavki koje će predstavljati inpute za drugačiji istraživački program. Dakle, alternativne pretpostavke bile bi: 1) pozitivan razvoj mladih je najefikasnija strategija prevencije rizičnih ponašanja i poremećaja u ponašanju adolescenata; 2) relacije između različitih činilaca socijalnog razvoja mladih su nelinearne i dinamične; 3) stresne okolnosti utiču na razvoj adaptivnog, 
a ne disfunkcionalnog ponašanja; 4) rizična ponašanja adolescenata mogu imati funkcionalnu vrednost u ostvarivanju socijalnih ciljeva.

\section{Razmatranje pretpostavki u odnosu na auditorijum}

Ideja da je rizično ponašanje adolescenata oblikovano sklopom individualnih i kontekstualnih činilaca predstavlja lajt motiv mnogih pedagoških i psiholoških istraživanja prevencije. Upravo zbog te činjenice su rizični i protektivni faktori dovedeni u poziciju veoma atraktivnog interdisciplinarnog koncepta. Sa jedne strane, imajući u vidu ekstra-istraživački tretman koncepta rizičnih i protektivnih činilaca u svetskoj literaturi, njegova radikalna problematizacija može biti percipiran kao irelevantna (apsurdna). S druge strane, dovođenje u pitanje pretpostavki konvencijalnih studija može biti pozdravljeno od strane različitih grupacija istraživača koje zagovaraju drugačije teorijsko-metodološke stavove.

\section{Evaluiranje alternativnih pretpostavki}

Osnovni zadatak šeste komponente problematizacije jeste procena heurističkog potencijala alternativnih pretpostavki u konstruisanju inovativnih istraživačkih pitanja. Čak i bez detaljne analize postojeće literature, jasno je da će publiku kojoj su prethodno predstavljene alternativne pretpostavke namenjene činiti istraživači koji proučavaju socijalni razvoj mladih. Međutim, značajno je primetiti da će varijabilne recepcije $\mathrm{i}$ intepretacije pretpostavki biti u značajnoj meri disciplinarno determinisane (Alvesson \& Sandberg, 2013).

Da li će alternativne pretpostavke biti percipirane kao irelevantne, apsurdne ili interesantne? Hoće li alternativne pretpostavke voditi ka inovativnijim i uticajnijim programima istraživanja? Odgovore na ova pitanje treba potražiti u delovanju bitnih personalnih i kontekstualnih faktora. U svakom slučaju, alternativne pretpostavke nisu nužno bolje od onih koje su problematizovane, niti je reč o paradigmatskim promenama. Kako ukazuju Alvesson i Sandberg (Alvesson \& Sandberg, 2013), postoji mnoštvo opcija između ekstremno konzervativnih istraživanja i sugerisanja potpuno novog intelektualnog pogleda na svet.

\section{ZAKLJUČAK}

Postoje brojni intelektualni razlozi, profesionalne norme i institucionalni mehanizmi koji snažno usmeravaju kvalitativne i kvantitativne istraživače ka internalizovanju - ili barem javnom preferiranju - konvencionalnog modusa kreiranja istraživačkih pitanja. Na nivou pojedinca - istraživača i na nivou zajednice - paradigme, uočavanje ili kreiranje praznina u literaturi predstavlja dominantan obrazac formulisanja istraživačkih pitanja. Imajući u vidu da se na taj način pretpostavke postojećih teorija, manje ili više, programirano reprodukuju, 
malo je verovatno da će inkrementalna istraživanja rezultirati originalnim i uticajnim doprinosima.

Osnovna ambicija ovog rada bila je da se ukaže na to problematizacija predstavlja očiglednu, ali retko upotrebljavanu strategiju formulisanja inovativnih istraživačkih pitanja. Afirmisan je pristup koji kritički analizira i konstruktivno ukazuje na slabosti premisa, perspektiva, implikacija, jezika i drugih elemenata dominantnih teorijskih orijentacija, sa ciljem kreiranja skupa zanimljivih alternativa. Preciznije rečeno, problematizacija pretpostavlja uočavanje, artikulisanje i kritikovanje rukovodećih pretpostavki postojeće literature i, na osnovu toga, formulisanje istraživačkih pitanja koja podstiču razvoj interesantnog i relevantnog znanja. 
Stefan R. Ninković, Olivera Č. Knežević Florić

Department of Pedagogy, Faculty of Philosophy, University of Novi Sad

\title{
CREATING INNOVATIVE RESEARCH QUESTIONS: A PROBLEMATIZATION PERSPECTIVE
}

\begin{abstract}
SUMMARY
There are a number of intellectual reasons, professional norms and institutional mechanisms by which qualitative and quantitative research have been strongly driven towards the internalization - at least publicly preferred - of conventional modes of formulating research questions. At individual (researcher) and community (paradigm) levels, gap-spotting is the most common mode of formulating research questions. Given that in this way the assumptions of existing theoretical orientations are more or less merely reproduced in a programmed manner, it is unlikely that such studies will result in original and influential contributions. In this context, it is reasonable to ask the following questions: Did the educational research lost its way? Do educational researchers have anything to say? Has the research in education become a routine (uninspiring), isomorphic and irrelevant?

The paper indicates that problematization makes an obvious but seldom used alternative strategy of formulating research questions. The basic idea of the paper is to promote the approach that critically and constructively analyze and indicate the limited nature of premises, perspectives, implications, language and other elements of dominant theoretical orientations, aimed at challenging them and considering a set of alternative options instead. Specifically, problematization means locating, articulating and criticizing the assumptions of existing literature, and thus, formulating research questions that encourage the development of interesting and relevant knowledge.

It has been found that problematization cannot be reduced to a fixed or even strictly routine procedure, since it necessarily involves a dialectical and dialogical process. On one hand, the principle of "everything is possible" by no means can be applied in problematization; on the other hand, problematization cannot be conducted in any universally perfect way. As a dynamic nonlinear process, it is always situated in the reality of research practice. In other words, at each application, problematization is defined over and over again - it becomes what it is only in user's hands. Finally, the paper concludes with the statement that despite the pervasive tendency of researchers to implement standardized and isomorphic studies, educational research are possible to return to the "right path", which includes creating original scientific knowledge, relevant both from social and pedagogical perspectives.
\end{abstract}

Keywords: educational research, research questions, problematization, critical thinking 


\section{LITERATURA}

Abbott, A. (2004). Methods of Discovery: Heuristics for the Social Sciences. London: W. W. Norton \& Company.

Alvesson, M., \& Sandberg, J. (2011). Generating research questions through problematization. Academy of Management Review, 36(2), 247-271.

Alvesson, M., \& Sandberg, J. (2013). Constructing research questions: Doing interesting research. London: Sage.

Alvesson, M., \& Sandberg, J. (2014). Habitat and habitus: Boxed-in versus box-breaking research. Organization Studies, 35(7), 967-987. doi: 10.1177/0170840614530916

Alvesson, M., \& Sköldberg, K. (2009). Reflexive methodology: New vistas for qualitative research. London: Sage.

Bašić, J. (2009). Teorije prevencije: prevencija poremećaja u ponašanju i rizičnih ponašanja djece $i$ mladih. Zagreb: Školska knjiga.

Becher, T., \& Trowler, P. (2001). Academic tribes and territories: Intellectual enquiry and the culture of disciplines. McGraw-Hill Education.

Biesta, G. J. (2010). Why 'what works' still won't work: From evidence-based education to value-based education. Studies in Philosophy and Education, 29(5), 491-503. DOI 10.1007/ s11217-010-9191-x

Bronfenbrener, J. (1997). Ekologija ljudskog razvoja - prirodni i dizajnirani eksperimenti. Beograd: Zavod za udžbenike.

Caravita, S., Di Blasio, P., \& Salmivalli, C. (2009). Unique and interactive effects of empathy and social status on involvement in bullying. Social development, 18(1), 140-163. DOI: $10.1111 / \mathrm{j} .1467-9507.2008 .00465 . \mathrm{x}$

Ellis, B. J., Del Giudice, M., Dishion, T. J., Figueredo, A. J., Gray, P., Griskevicius, V., et al. (2012). The evolutionary basis of risky adolescent behavior: implications for science, policy, and practice. Developmental psychology, 48(3), 598-623. http://dx.doi.org/10.1037/ a0026220

Feyerabend, P. (1987). Protiv metode: Skica jedne anarhističke teorije spoznaje. Sarajevo: Veselin Masleša.

Hawkins, J. D., Catalano, R. F., \& Miller, J. Y. (1992). Risk and protective factors for alcohol and other drug problems in adolescence and early adulthood: implications for substance abuse prevention. Psychological Bulletin, 112(1), 64-105. http://dx.doi.org/10.1037/00332909.112.1.64

Heath, C., \& Heath, D. (2007). Made to stick: Why some ideas survive and others die. New York: Random House.

Hostetler, K. (2005). What is "good" education research?. Educational Researcher, 34(6), 16-21. doi: 10.3102/0013189X034006016

Howe, K. R. (2009). Positivist dogmas, rhetoric, and the education science question. Educational Researcher, 38(6), 428-440. doi: 10.3102/0013189X09342003

Kärnä, A., Voeten, M., Little, T. D., Poskiparta, E., Kaljonen, A., \& Salmivalli, C. (2011). A large scale evaluation of the KiVa antibullying program: Grades 4-6. Child Development, 82(1), 311-330. DOI: 10.1111/j.1467-8624.2010.01557.x

Kennedy, M. M. (2010). Attribution error and the quest for teacher quality. Educational Researcher, 39(8), 591-598. doi: 10.3102/0013189X10390804

Law, J. (2004). After method: Mess in social science research. London: Routledge. 
Leana, C. R., \& Pil, F. K. (2006). Social capital and organizational performance: Evidence from urban public schools. Organization Science, 17(3), 353-366. http://dx.doi.org/10.1287/ orsc. 1060.0191

Lösel, F., \& Farrington, D. P. (2012). Direct protective and buffering protective factors in the development of youth violence. American Journal of Preventive Medicine, 43(2), S8-S23. http://dx.doi.org/10.1016/j.amepre.2012.04.029

Meklaren, P. (2013). Če Gevara, Paulo Freire i pedagogija revolucije. Beograd: Eduka.

Milenković, M. (2006). Šta je (bila) antropološka refleksivnost. Etnoantropološki problemi, 1(2), 157-185.

Milenković, M. (2007). Istorija postmoderne antropologije. Posle postmodernizma. Beograd: Srpski geneaološki centar.

Ninković, S. \& Knežević Florić (2014). Utemeljena teorija: znanje za teoriju i praksu. Nastava $i$ vaspitanje, 4, 581-593.

Pluess, M., \& Belsky, J. (2013). Vantage sensitivity: Individual differences in response to positive experiences. Psychological Bulletin, 139(4), 901-916. http://dx.doi.org/10.1037/ a0030196

Reyna, V. F., \& Farley, F. (2006). Risk and rationality in adolescent decision making implications for theory, practice, and public policy. Psychological science in the public interest, 7(1), 1-44. doi: 10.1111/j.1529-1006.2006.00026.x

Sandberg, J., \& Alvesson, M. (2011). Ways of constructing research questions: gap-spotting or problematization?. Organization, 18(1), 23-44. doi: 10.1177/1350508410372151

Sandelowski, M. (2010). What's in a name? Qualitative description revisited. Research in nursing \& health, 33(1), 77-84. DOI: 10.1002/nur.20362

Steinberg, L. (2008). A social neuroscience perspective on adolescent risk-taking. Developmental review, 28(1), 78-106. doi:10.1016/j.dr.2007.08.002

Ungar, M. (2004). A constructionist discourse on resilience multiple contexts, multiple realities among at-risk children and youth. Youth \& society, 35(3), 341-365. doi: 10.1177/0044118X03257030

Van de Ven, A. H. (2007). Engaged scholarship: a guide for organizational and social research: a guide for organizational and social research. Oxford: Oxford University Press. 